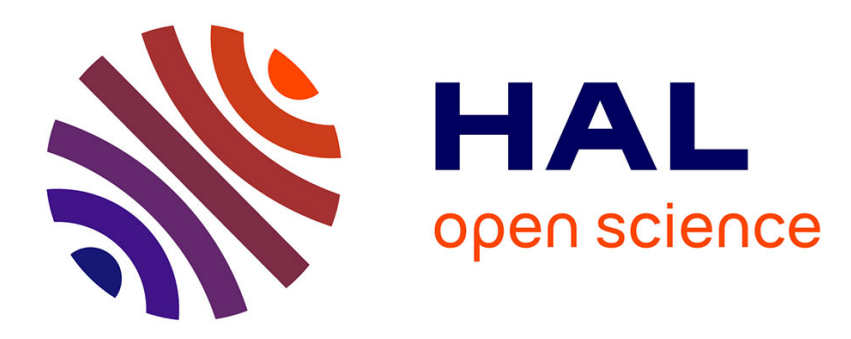

\title{
The importance of binaural hearing for noise valuation
}

\author{
M. Bodden
}

\section{To cite this version:}

M. Bodden. The importance of binaural hearing for noise valuation. Journal de Physique IV Proceedings, 1994, 04 (C5), pp.C5-399-C5-402. 10.1051/.jp4:1994583 . jpa-00253078

\section{HAL Id: jpa-00253078 https://hal.science/jpa-00253078}

Submitted on 1 Jan 1994

HAL is a multi-disciplinary open access archive for the deposit and dissemination of scientific research documents, whether they are published or not. The documents may come from teaching and research institutions in France or abroad, or from public or private research centers.
L'archive ouverte pluridisciplinaire HAL, est destinée au dépôt et à la diffusion de documents scientifiques de niveau recherche, publiés ou non, émanant des établissements d'enseignement et de recherche français ou étrangers, des laboratoires publics ou privés. 


\title{
The importance of binaural hearing for noise valuation
}

\section{BODDEN}

\author{
Lehrstuhl für allg. Elektrotechnik und Akustik, Ruhr-Universität Bochum, 44780 Bochum, Germany
}

\begin{abstract}
In a project that has been funded by the German Ministery of Research and Technology (BMFT) fundamental questions of noise valuation have been addressed by an interdisciplinary research consortium. The aim of the project was to provide knowledge that will lead to a new, binaural and aurally-adequate measurement technique which can especially be used for the valuation of the effects of noise for levels below the legislative limit of $85 \mathrm{~dB}(\mathrm{~A})$ at workshop places. The investigations have proven that the spatial distribution of sounds has an influence on physiological responses of humans exposed to noise, and that psychoacoustic attributes, e.g., loudness, depend on the direction of sound incidence. In consequence an aurally-adequate measurement technique has to consider binaural processing. A binaural model that could be used for this task is presented.
\end{abstract}

\section{INTRODUCTION}

The measurement technique that is conventionally used for the valuation of the effects of noise differs in some important aspects from the way humans perceive and evaluate sounds:

- due to the shapes of ears, head and shoulders the outer ears form directional filters. The conventional technique uses a unidirectional microphone and is thus not able to consider these effects.

- the human auditory system makes use of two input signals, supplied from the left and right ear, which are combined in the auditory pathway. This binaural processing offers a lot of advantages, e.g., spatial hearing and binaural selectivity. The conventional technique uses only one microphone.

- auditory sensations are characterised by psychoacoustic attributes like loudness, sharpness and roughness, and do not only depend on the sound pressure level.

Regarding these differences it becomes obvious that the conventional technique can not generally be used to valuate the effects of noise. If we consider for example a complex sound situation, in which several noises are emitted from different positions, the conventional technique will perform a simple summation of the sound pressure levels of all signals. In contrast to that the human auditory system performs a selective analysis of the underlying situation, separating the sources from each other and assigning to them their own respective perceptual attributes. Thus the resulting valuation is not performed on the physical sum of the signals, but is a combination of the evaluation of each individual signal. This topic has been addressed by a project which has been funded by the German Federal Ministery of Research and Technology (BMFT), and the results presented here mainly stem from this project. 
Fingerpulse amplitude (FPA), skin conductance response (SCR), heart frequency (HF) and electro-myogram of $\mathrm{m}$. frontalis (EMG) of subjects exposed to noise have been measured at Düsseldorf University (see NOTBOHM et al., 1992). The first series of experiments addressed the question whether a difference in the physiological responses can be recorded if signals which are played back via headphones have either been recorded with one unidirectional microphone (representing the conventional technique) or a dummy head (representing the binaural technique). Three different noises have been recorded at workshop places of wood- and metal-processing industries (circular saw, hacksaw and engine construction), supplemented by pink noise as a control stimulus. All signals have been adjusted to the same level of 83 $\mathrm{dB}(\mathrm{A})$. This level has been chosen because german legislative has fixed a maximum level of $85 \mathrm{~dB}(\mathrm{~A})$ at workshop places. Fig. 1 shows an example for responses to hacksaw noise (averaged FPA values for intervals of $5 \mathrm{~s}$ ). The responses to the dummy head recordings are significantly higher than those to the con-

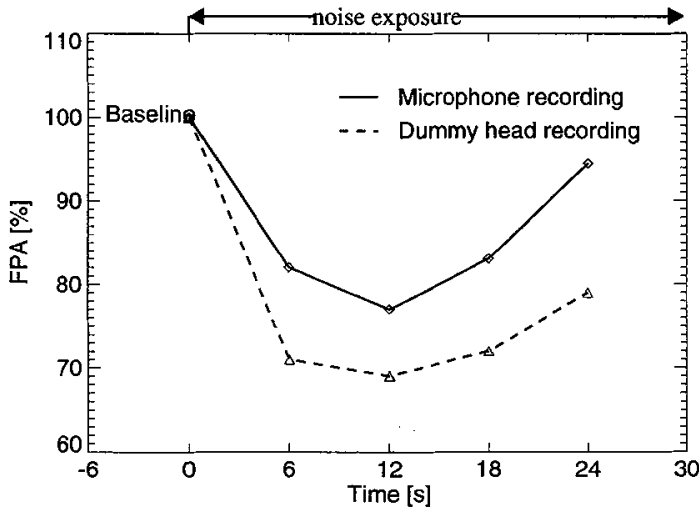

Fig. 1: Fingerpulse amplitude for hacksaw noise recorded with a unidirectional micro-phone (solid line) or a dummy head (broken line).

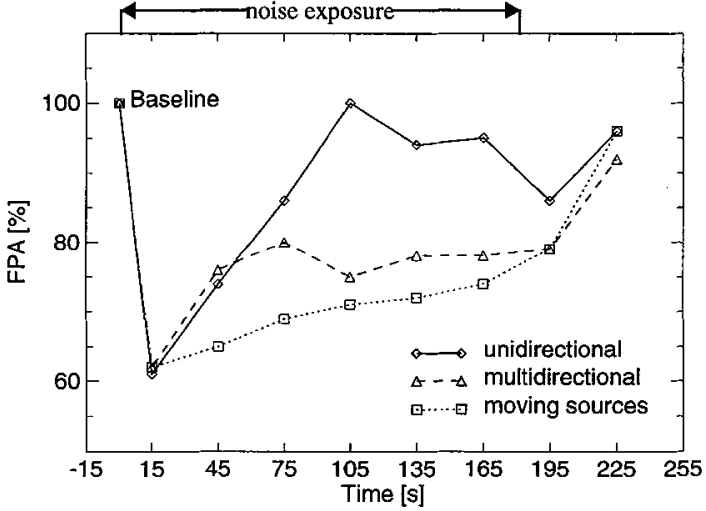

Fig. 2: Fingerpulse amplitude for uncorrelated pink noise in the Uni-directional, multi-directional and moving situations.

ventional recordings. This is consistent for all stimuli, but more prominent for the industrial noises. The results prove that binaural processing plays a role with regard to the physiological responses of humans exposed to noise.

The subsequent series of experiments were intended to investigate on the influence on the spatial distribution of sounds. Now a uni-directional situation (two sources at the same position), a multi-directional situation (two sources at different azimuths) and a moving situation (two sources which move from the sides in opposite directions and cross in front) have been compared at a common level of $84 \mathrm{~dB}(\mathrm{~A})$. Two uncorrelated pink noises have been used as stimuli. In this series a significant difference in the responses to the different situations only was observed for the fingerpulse amplitude. The results are depicted in Fig. 2. A difference between the situations can be remarked after the initial reaction (the first $30 \mathrm{~s}$ ), when a reregulation mechanism can be observed for the uni-directional situation. This re-regulation mechanism is delayed for the multi-directional and moving situations, the baseline is not reached any more.

\section{PSYCHOACOUSTICAL INVESTIGATIONS}

In a first series of psychoacoustic experiments performed at Oldenburg University masking of sinusoidal signals in different masking sound fields (pink noise) have been investigated. 6 loudspeakers surrounding the subject have been used to build a plane sound field (one speaker active), a uni-coherent sound field (all loudspeakers emit identical pink noises) or a diffuse sound field (all loudspeakers emit uncorrelated pink noises). First, the masking level of sinusoidal test signals emitted from $60^{\circ}$ have been measured in the three masking fields. The results depicted in Fig. 3 state that the masking highly depends on the type of masking sound field. Differences between the sound fields of up to $12 \mathrm{~dB}$ can be observed. 


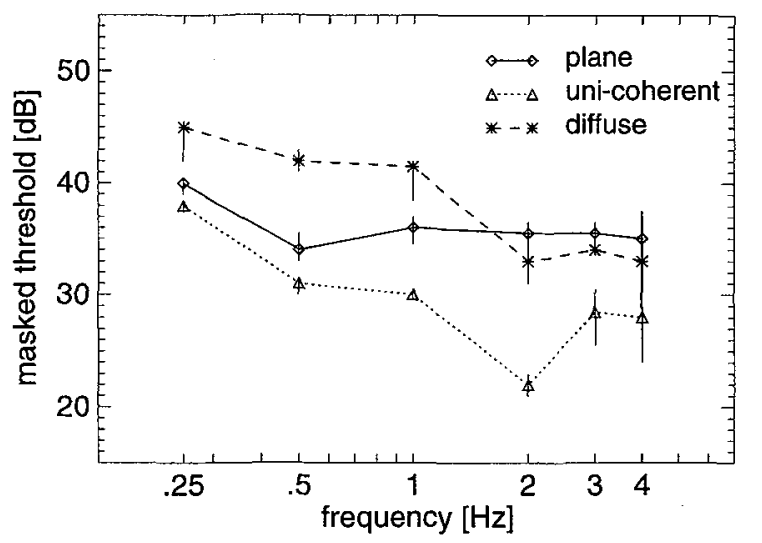

Fig. 3: Masked threshold of a simusoidal signal in plane, uni-coherent and diffuse masker sound fields (pink noises).

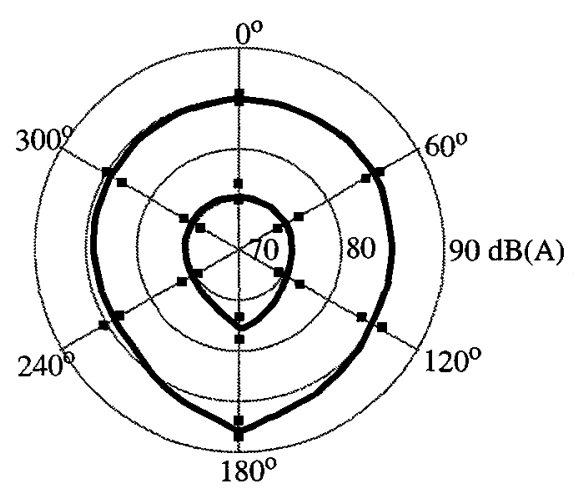

Fig. 4: Curves of equal loudness for pink noise as a function of sound incidence. Reference: diffuse sound field of 75.4 or $85.3 \mathrm{~dB}(\mathrm{~A})$.

Next, binaural loudness perception was investigated in more detail in a second series of psychoacoustic experiments. The task of the subjects was to adjust the level of the test signal (pink noise emitted from one of the six loudspeakers) so that it equals the loudness of a reference signal (diffuse sound field at 75.4 and $85.3 \mathrm{~dB}(\mathrm{~A})$ ) while the direction of incidence of the test signal was varied. The results of experiments with 8 subjects are depicted in Fig. 4. The sound pressure level for equal loudness differs from the sound pressure level of the diffuse reference sound for up to $3 \mathrm{~dB}(\mathrm{~A})$. The backward direction shows the lowest sensitivity with regard to loudness perception, whereas the directions of $\pm 60^{\circ}$ show the highest sensitivity. The frontal direction is similar to the diffuse reference.

\section{MODELING BINAURAL HEARING}

The results of the physiological and psychoacoustic investigations can be interpreted in such a manner that a noise valuation technique has to involve spatially selective processing. During the run of the project Bochum University investigated on the possibility to employ a model of the binaural human auditory system that is able to reproduce major aspects of sound localization and binaural selectivity. The model that was used as a basis for the project has been developed by Lindemann (1986) and Gaik (1993). It is based on an interaural cross-correlation function that has for example been extended by a mechanism of contralateral inhibition, monaural processors, and an adaptation to head-transfer-functions. The resulting model is able to reproduce influences of interaural differences in time (IDT) and intensity (IID) and, what is more important, of the combination of both. For details on the model please refer to the literature mentioned above.

The output of the model can be regarded as a simulation of neural excitations. Those neural excitations offer the decisive advantage that the spatial distribution becomes available for the analysis as a further dimension. The neural excitation patterns are analyzed to predict the positions of hearing events - up to today restricted to the projection of the position into the frontal horizontal plane (azimuth) (for details see Bodden, 1993). Fig. 5 shows the predicted azimuth as a function of time for two simultaneous speakers at $-30^{\circ}$ and $+40^{\circ}$, Fig. 6 the moving sound sources that have been used in the measurements of physiological responses. The example shows that even multiple moving sound sources can be traced by the algorithm.

The results shows that the binaural model can be used to perform an analysis of the spatial distribution of the sound field. In a further extension of the model Bodden $(1992,1993)$ showed that it can be used as a basis for a Cocktail-Party-Processor, that is, for a system that is able to suppress interfering signals coming from different directions of incidence. 


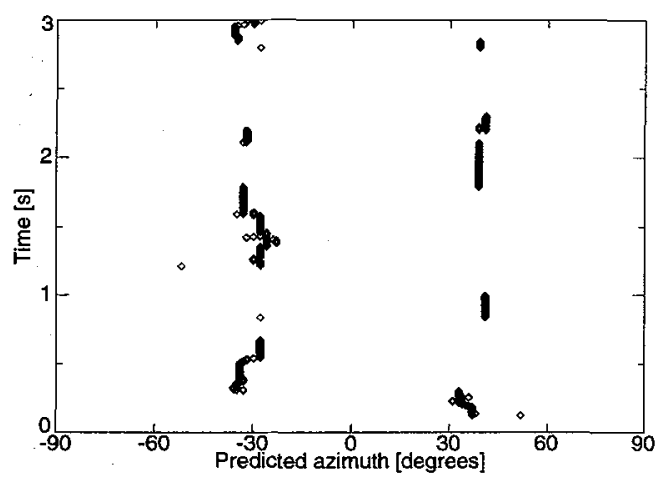

Fig. 5: Predicted azimuth of two concurrent speakers.

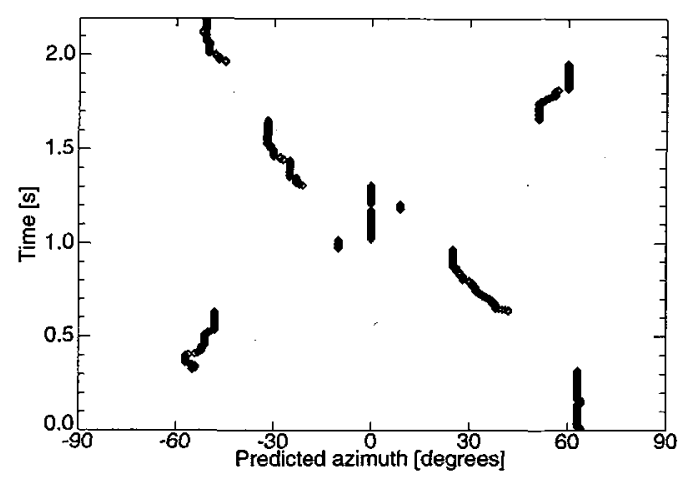

Fig. 6: Predicted azimuth of two alternating sound sources moving in opposite directions.

\section{CONCLUSIONS}

The investigations described in this paper have proven that binaural processing has an influence on the physiological responses of humans exposed to noises even for levels that are below the limit of $85 \mathrm{~dB}(\mathrm{~A})$. The spatial distribution of sound seems to be a parameter that influences physiological responses as well as characteristical perceptual attributes like loudness, sharpness and roughness. Thus a method for the valuation of the effects of noise has to consider this binaural processing, and therefore has to employ a model of binaural interaction. The investigations have to be continued in order to transfer the results into an aurally-adequate measurement technique (Genuit, 1992) and to develop extensions to the valid legislative norms and standards. This new binaural noise valuation technique is not intended to supersede the conventional technique, but to extend it especially for situations in which people complain about the effects of noise in the range of levels under $85 \mathrm{~dB}(\mathrm{~A})$.

\section{ACKNOWLEDGEMENTS}

The results presented in this paper are mainly based on investigations of an interdisciplinary research project. The author wishes to thank those who participated at Düsseldorf University, Oldenburg University, Bochum University and Head acoustics as well as the BMFT for financial support.

\section{LITERATURE}

Abschlußbericht AuT-Forschungs-Projekt 01 HK 029/8: Entwicklung einer Meßtechnik mit Berücksichtigung der psychoakustischen Eigenschaften des Nachrichtenempfängers "Menschliches Gehör" zur physiologischen Bewertung von Lärmwirkung.

BODDEN, M. (1992): Binaurale Signalverarbeitung: Modellierung der Richtungserkennung und des Cocktail-Party-Effektes. Fortschr.-Ber. VDI. Düsseldorf: VDI-Verlag 1992.

BODDEN, M. (1993): Modeling Human Sound Source Localization and the Cocktail-Party-Effect. Acta Acustica 1(1), 43-55.

GAIK, W. (1993): Combined Evaluation of Interaural Time and Intensity Differences: Psychoacoustic Results and Computer Modeling. J. Acoustical Society of America Vol. 94 No. 1, 98-110.

GENUIT, K. (1992): Significance of Binaural Technology for aurally-adequate Sound Measurement Technique. Proc. 14th Intern. Congress on Acoustics (ICA), Beijing, L3-3.

LINDEMANN, W. (1986): Extension of a binaural cross-correlation model by contralateral inhibition. I. Simulation of lateralization of stationary signals. J. Acoustical Society of America, 80, 1608-1622.

NOTBOHM, G.; SCHWARZE, S.; JANSEN, G. (1992): Noise Evaluation based on Binaural Hearing. Proc. 14th Intern. Congress on Acoustics (ICA), Beijing, H2-2. 